\title{
Erratum to: Renal Protective Effects of Extracts from Guava Fruit (Psidium guajava L.) in Diabetic Mice
}

\author{
Chia-Yu Lin • Mei-Chin Yin
}

Published online: 7 September 2012

(C) Springer Science+Business Media, Inc. 2012

Erratum to: Plant Foods Hum Nutr (2012)

DOI: 10.1007/s11130-012-0294-0

The original version of this article unfortunately contained a mistake. One author name is incorrect, Chia-Yun Lin should be Chia-Yu Lin.

The online version of the original article can be found at http://dx.doi.org/ 10.1007/s11130-012-0294-0.

C.-Y. Lin $\cdot$ M.-C. Yin

Department of Health and Nutrition Biotechnology,

Asia University,

Taichung City, Taiwan

M.-C. Yin $(\square)$

Department of Nutrition, China Medical University,

91, Hsueh-shih Rd.,

Taichung City, Taiwan

e-mail: mcyin@mail.cmu.edu.tw 